This item was submitted to Loughborough's Research Repository by the author.

Items in Figshare are protected by copyright, with all rights reserved, unless otherwise indicated.

\title{
Extending product lifetimes through WEEE reuse and repair: Opportunities and challenges in the UK
}

\section{PLEASE CITE THE PUBLISHED VERSION}

https://doi.org/10.1109/EGG.2016.7829857

\section{PUBLISHER}

(C) Fraunhofer IZM. Published by the IEEE

VERSION

AM (Accepted Manuscript)

\section{LICENCE}

CC BY-NC-ND 4.0

\section{REPOSITORY RECORD}

Cole, Christine, Tim Cooper, and Alex Gnanapragasam. 2019. "Extending Product Lifetimes Through WEEE Reuse and Repair: Opportunities and Challenges in the UK". figshare. https://hdl.handle.net/2134/34805. 


\title{
Extending Product Lifetimes through WEEE Reuse and Repair: Opportunities and Challenges in the UK
}

Electronics Goes Green, September 7-9, 2016, Berlin.

\author{
Authors \\ Christine Cole1*, Tim Cooper1, Alex Gnanapragasam1 \\ 1 Nottingham Trent University, Nottingham, UK \\ * Corresponding Author, c.cole@lboro.ac.uk
}

\section{Abstract}

Discarded electrical and electronic equipment (EEE) is a rapidly growing waste stream. This has increased, in part, because advances in technology have contributed to shorter product lifetimes. As such, waste electrical and electronic equipment (WEEE) has received increasing attention from policy makers. Previous research has revealed the large proportion of end-of-life consumer electronics disposed of through residual waste collections and destined for landfill disposal or incineration. This represents a missed opportunity for extending their lifetime by facilitating recovery for repair or reuse.

This paper outlines current policy context, explores routes for end-of-life EEE in the UK and examines opportunities for product life extension through reuse. A series of semi-structured interviews were undertaken to determine if current collection system for end-of-life equipment in the UK adequately encourages increased repair and reuse in line with UK Government's waste reduction programme, or whether there is excessive focus on recycling. The findings are reported to discuss if UK policy framework is adequate to embed legislative requirements and improve current practices and whether the current system promotes awareness and understanding by householders sufficient to encourage behaviour change.

\section{Introduction}

Increased manufacturing and use of electrical and electronic equipment (EEE) in recent years due to technological innovations and new applications of EEE has led to a rapid growth in the proliferation of waste electrical and electronic equipment (WEEE). Generation of WEEE globally in 2014 was estimated at 41.8Mt, with 1.5Mt of this generated in the UK [1]. Environmental pressures from an increase in waste generation are well documented; these include the loss of useful material and energy resources, and increase in air, water and land pollution from waste treatment methods [2], [3]. Approximately. 0.7Mt of European Union (EU) WEEE is disposed of through residual waste streams, with either incineration or landfill, recognised sources of greenhouse gas emissions, as their final destination [1]. Additionally, incorrect disposal and treatment of WEEE poses threats to human health [7], particularly when involving illegal exports [5], [6].

All products require energy inputs during manufacturing; but it is the energy intensive processes involved in manufacturing of most EEE that results in these products containing high levels of embodied carbon [7]. The detrimental impact of material production and processing is inexorable [8] as product lifetimes decline [9], [10] in response to demand for continual innovation and upgrade [11], [12]. Attention should be paid to embodied carbon contained within products, particularly those manufactured from the most carbon intensive materials such as steel, aluminium, cement, plastic and paper, [13]. The production of EEE is resource- intensive, both from energy used during production and distribution stages, but also in the materials used. In the UK, production of EEE accounts for a significant share of the use and consumption of steel and plastic [14], with 55\% of EEE incorporating steel, $27 \%$ of EEE including plastic and $2 \%$ containing aluminium. In addition to this, many contain various other valuable and scarce resources [5], [7], [15] and hazardous materials such as heavy metals and chemicals [1]. Many EEE products also have high energy consumption during their use phase. To some extent, this has been addressed by focusing on improving energy efficiency of electrical items [16]. However, increasingly higher demand for products, with declining product lifetimes, is leading to more frequent replacement of them [17], which means that production processes have been accelerated, and this "rebound effect" offsets gains from improved efficiency [18].

Improving material efficiency [19] and ensuring a product reaches its optimal lifespan would minimise emissions throughout its life cycle from design and manufacturing, to disposal [20]. If targets for reductions in greenhouse gas emission are to be reached, then reuse needs to be included as part of a whole life cycle approach to embodied carbon [21]. Ways of addressing this are to increase product longevity - either by extending a product's first life 
or addressing issues of repair and reuse [22] and recycling [23]. Reusing products, and therefore extending the use of that item beyond the point where it has been discarded by its first user would be preferable to recycling or disposal [24] as this is the least energy intensive solution, though it is often overlooked [25].

\section{Current policy contexts}

Legislation is the primary driver for sustainable waste management practices in the UK [26]. European environmental policy has evolved significantly since the 1970s when the Waste Framework Directive (75/442/EEC) introduced the definition of waste and concepts aimed at preventing its detrimental impacts on human health and the environment. The waste hierarchy set out a preferred order for waste treatment and disposal methods, based on environmental impacts of each option. The Basel Convention, a global treaty implemented by EU and UK governments in 1992, sought to control and reduce transboundary movements of hazardous waste to restrict hazardous practices of treating WEEE [27].

Better management of most types of EEE is addressed by the WEEE Directive (2002/96/EC) and subsequent recast Directive (2012/19/EC). This recognises WEEE has to be treated differently to general waste because it contains valuable materials that can be recovered [28], as well as highly toxic materials which must be treated correctly [29]. It also recognises the importance of reuse, particularly of whole appliances, by inclusion of the "preparation for reuse" guidelines for WEEE, its components and consumables. Additionally, the Ecodesign Directive (2009/125/EC), whilst initially applied to improving energy performance of products, could be used to address reuse. Material specifications for EEE in the UK are addressed by the Restriction of the Use of Certain Hazardous Substances in Electrical and Electronic Equipment Directive (2011/65/EU), which limits various toxic materials in consumer durables (e.g. lead, mercury, cadmium etc.) requiring the production of less toxic products [30]. There are also opportunities for producers, waste management companies and local authorities to make reuse habitual, which include raising awareness and encouraging behaviour change [31]. Potential for service- based business models to produce reductions in resource demands [17] was recognised in the EU's recent Circular Economy Package [32].

\section{Producer Responsibility (PR)}

The WEEE Directive seeks to encourage, repair, reuse and recycling through improved product design, by providing a financial incentive for manufacturers to produce less harmful goods, which are easier to reuse and recycle, use less virgin material and energy, and contain fewer and less hazardous materials. Producer Responsibility (PR) is a policy approach to reduce environmental impacts [33]. The intention is that end-of-life consequences inform design processes to a greater extent, thereby reducing the use of natural resources, prevent waste, closing material loops and producing less harmful products [34]. In order to do this, PR seeks to extend a producer's responsibility for a product to post-consumer stage of its life cycle [35]. Additionally, within the WEEE Directive there is a requirement for producers to provide information, logistics and collection to facilitate sustainable treatment of waste originating from their own products, either individually or as part of a collective scheme:

- Individual responsibility - producers take responsibility for end-of-life management of its own products.

- Collective responsibility - a group of producers collectively fulfil responsibilities for end-of-life management of products regardless of the brand.

Individual producer responsibility schemes appear to be more favourable, in principle, to a producer committed to addressing environmental issues such as recyclability or reuse [36]. Individual producers benefit from any changes implemented to design and manufacturing processes to reduce end-of-life costs. Drivers of eco-design are strengthened when individual producers are made directly responsible for total end-of-life costs: namely collection, dismantling, re-use and high-levels of material recycling [37]. However, reverse logistics of individual producers organising collection of their own products from end-users is claimed to be impractical and not economically viable [38], [39]. Additionally, brand specific collection systems do not address problems posed by orphan products i.e. where manufacturers have gone out of business [34].

Collective responsibility schemes allow producers to share responsibility and cost for each other's end-of-life products. This reduces the incentive to make expensive design or manufacturing changes to reduce end-of-life environmental impacts or treatment costs because benefits of doing this will be shared collectively, whilst costs of being part of the scheme remain the same. Collective responsibility could offer economies of scale and improve the ease with which reverse logistics operate by offering consumers the convenience of one drop-off point for a number of items [40], [36]. However, in practice this has resulted in each producer effectively sharing the average costs of collectively recycling mixed categories of electrical products [41].

\section{Current Routes for End-of-Life EEE}

WEEE is generally treated as a post-consumer waste management problem [42], focusing on dismantling, recycling, and the management of toxic materials [43]. However, it is also a waste stream that contains valuable 
raw materials [44]. The challenges posed by this complex waste stream have seen a variety of different technologies and separation methods adopted to recover various elements [45].

There are many challenges to improving the end-of-life phase of small household EEE [44], [46]. Many disposal and treatment routes are available to consumers for unwanted EEE including second use, disassembly, formal collection with returns to brand aftersales service centres, certified recyclers, and designated dealers / retailers under the trade-in schemes [47]; more informal routes include selling to individuals, second-hand shops and home appliance repairers. Additionally, waste composition studies conducted by WRAP [48] show 8\% of household residual waste is EEE, destined for landfill or incineration with associated resource loss and environmental impacts [36].

The size, diversity and complexity of small WEEE, a heterogeneous mix of different items such as vacuum cleaners, home computers, laptops, mobile phones and small household appliances poses particular problems for recovery [30]. The small size of these items makes them particularly easy to dispose of in household waste bins. Small WEEE represents one of the largest fractions of WEEE waste by number of items, rather than by weight, and due to the nature of their size, these items contain a high proportion of hazardous materials [49].

Sustainable routes for end-of-life EEE rely on consumers making an effort to dispose of items responsibly. This may be difficult when information is lacking, and infrastructure is inadequate [26], but improves when there is access to local collections [50], with consumers returning WEEE through the channel most convenient to them [34]. Where collection systems do exist, they appear to favour recycling [51], but this is a destructive process, recovering a product's constituent elements at a fraction of their value [52], [53]. Additionally, whilst recycled materials offer energy savings in comparison to using raw materials, they still require energy for further manufacturing processes [54] and to some extent, require an input of virgin material to maintain quality [25]. Consumers often use different disposal routes for different types of electrical equipment [26], mainly due to a lack in awareness of appropriate disposal options, and the unavailability of segregated collection schemes [55]. Waste composition analysis of household waste streams shows many items of small WEEE present in the residual household waste stream, while larger WEEE items make up 51\% of the bulky waste stream [48]. King [54] found a wide disparity in the percentages of large household appliances (88\%) and IT equipment (40\%) collected for recycling.

Recovery processes concentrate on the collection of large items, informally salvaged "scrap metal”, or small items such as mobile phones and tablets with high value component materials [26], or active markets for reuse [56]. It is estimated that, in addition to the EEE already collected for reuse, 160,000 tonnes of WEEE in residual waste collections could have resale value of $£ 220$ million [57]. Furthermore, almost a quarter of WEEE taken to Household Waste Recycling Centres by consumers in the UK has a reuse value [58] with 23\% immediately resalable or would be resalable following simple repairs or refurbishment. In areas where Local Authorities operate segregated collections of WEEE to facilitate reuse of household waste, often in collaboration with local third sector organisations, they act as initiators for behaviour change [46], [59].

Product life extension through careful use and regular maintenance, repair, refurbishment and remanufacturing of used EEE is generally the best option in terms of environmental benefits [60]. In environmental terms, reuse ought to be more common than recycling and energy recovery [61] with the costs of simple refurbishing of some products being a fraction of the original manufacturing costs [51]. Often, only limited intervention is required to return a product to a serviceable condition [57], but this is perceived to be associated with high labour costs [47]. Additionally, with the exception of mobile phones [56], consumer demand for second-hand products is low [51]. Various barriers to reuse have been identified, these include issues about purchasing and owning second hand items. A British Standard, PAS141 [62] has been developed, specifically focusing on inspection and preparation for reuse of WEEE to provide consumers with confidence that the second-hand goods it covers reach a level of quality and safety [63]; PAS141 is comparable to the Revolve standard developed in Scotland. Reconditioned and remanufactured products face similar barriers to second-hand items with consumers. However, the benefits of reuse go beyond the provision of affordable items, often to low income households, and include waste reduction, environmental protection and social benefits including employment and training opportunities, often in third sector organisations [64], [65].

\section{Methodology}

An initial desk-based review of relevant literature was undertaken to further knowledge of current practices, challenges and implications for end-of-life electronics. The literature search included academic papers, industry and NGO reports, and both EU and UK legislation.

A purposive sampling method, whereby interviewees were selected to enable the research objectives to be met, was performed [66]. Interviewee selection was informed through an initial review of the literature and desk-based research. This was to ensure the interviewees had relevant knowledge and experience to inform the research and to provide meaningful information, thus meeting the principles identified by Kemper et al. [67], which include generating a database on the phenomenon being studied.

Interviewees in the form of policy-makers, environmental lobby groups, producer responsibility organisations, waste collection and waste management companies were identified and approached to take part in the interview 
phase of the research. Initial contact was made by email or telephone, allowing the researcher to explain the research area and to schedule an interview. The responsibilities, interests, key themes and challenges for discussion were identified in order to obtain evidence and opinions from across the sector which would enable a thorough investigation to take place.

A series of semi-structured face to face interviews were undertaken. Interviewees were selected to offer different perspectives, operational experiences, campaigning strategies, motivations and principal challenges faced in the area under investigation. A formalised set of questions were initially used, to ensure the goals and objectives of the study were met, a series of open ended questions allowed flexibility to expose answers that had not been anticipated through building a rapport with interviewees [68]. This offered differing observations from each of the interviewees. The purpose was to: -

- Assess potential systems available to improve the prospects for reuse and repair of WEEE, together with advantages and disadvantages.

- Critically evaluate the barriers identified to extending repair and reuse of WEEE in the UK and identify strategies to overcome them.

- $\quad$ Propose policy, regulatory and economic mechanisms that may be required to increase the quantity of WEEE that is repaired and reused in the UK.

Interviews were conducted to contextualise and explain gaps in literature, and enable stakeholders to shape and lead the debate to focus on topics that were central to their particular place in the life cycle of products

This paper reports on findings from the first nine interviews, each lasting approximately an hour. The interviews were audio- recorded, transcribed and analysed to identify both areas of agreement and disagreement; these are discussed to identify strategies and policy areas which could be improved. The analysis of the interview transcripts uses a general analytical framework [69] to identify priority areas for analysis using three separate stages, these were:

- Analysis of individual interviews to conduct initial categorisation and coding.

- Identification of common themes.

- Examination of common themes to establish any patterns between the perspectives of the stakeholders.

Data analysis ran concurrently with the data collection using the constant comparative method of a grounded theory approach [70]. This enabled earlier interviews to shape the selection of later interviewees and to allow themes to be explored comprehensively, whilst also supporting comparison with pre-existing literature and practice.

\section{Initial findings and analysis}

Initial findings from the nine interviews are presented and discussed below. The responses have been grouped into topics covered in the interviews and the responses evaluated through close reading of the transcripts in the context of identifying opportunities for reuse of EEE and the current legislative framework.

\subsection{Barriers to reuse}

A number of barriers to reuse were identified. Of the nine interviewees, eight expressed an opinion that local authority waste collection staff damage products that they collect and do little to protect any reuse potential those items may have had.

“Collection systems remove products as quickly as possible to a disposal point, taking little interest in careful handling of items, this reduces the chance of reuse”. (Furniture Reuse Network).

The operational processes of local authority waste collections and household waste recycling centres are better suited to destructive recycling process or "last minute scrap salvage" (reuse charity) than usable goods recovery. In addition, recycling targets discourage reuse: once items are classed as 'waste' the easier option seems to be recycling. The mechanised system of recycling requires a lower skill base and does not require any specialist testing, and repair skills required to ensure items are safe to sell for reuse. These repair skills are also seen to increase the sale price of reused items.

“Making sure electrical items are suitable for reuse is not an electrician's job, it goes beyond simple PAT testing. This is a job for a highly skilled domestic engineer”. (Compliance scheme operator).

Suggestions to increase reuse of EEE included moving away from waste management systems to reuse recovery systems. Three interviewees, those from a national reuse charity, furniture reuse organisation and a reuse business 
identified that this could be achieved by utilising retailer's reverse logistics, which are perceived as better suited to handling goods carefully and preserving reuse potential.

"It probably should have been done in a different way. There's a whole supply chain that could've done reverse logistics differently.” (Local authority advisory body)

The care taken by delivery teams handling new goods should be duplicated by those handling reusable goods in order to prevent damage. This happens in practice in some organisations. One national charity uses delivery staff trained to handle goods carefully, this ensures better opportunities for reuse. A network to handle reusable goods outside local authority waste collection systems would be a good starting point for increasing reuse, it was suggested that amending producer responsibility could facilitate this.

\subsection{Producer Responsibility}

Producer responsibility, as it is currently applied in the UK, requires improvement. Several interviewees, notably those from an environmental lobby group, compliance scheme and a local authority advisory body suggested that producers should take more responsibility for the end-of-life phase, perhaps by organising more collections and increasing reverse logistics.

"There's a role there for the producers to kind of come in and say, 'Right, in order to help with this, we'll help fund local authority schemes.”' (Local Authority advisory body).

Whilst this is a rather simplified notion, it may have some foundation. The premise is that finance from PR could be used to fund WEEE collection systems. Whilst this currently happens through the compliance scheme model, which producers fund, it was implied that this concentrates on achieving recycling targets in preference to maximising reuse.

There were some conflicting views on communicating the environmental impact of products to consumers, with the environmental lobby group suggesting that PR could be used to finance a public awareness campaign, possibly using on-pack information. Whilst the local authority advisory body said that under no circumstances should the consumer be told the cost of disposable as this might create resistance towards recycling.

Other proposals include ensuring that the environmental impact of different products is reconciled with the producer responsibility fees by using differentiated fees for products. If fees were calculated on the whole life impact (rather than end of life costs) and calculated using life cycle assessments, or carbon, water and resource footprints, they could indicate to the consumer which goods are the most harmful to the environment.

\subsection{Standards}

There was some acceptance that standards for reuse are "essential" for testing and repair of items destined for reuse. This would address both the stigma associated with buying used goods and address safety concerns (fire and electric shocks were both cited). Accreditation and auditing of test and repair services, issuing warranties or guarantees for repair were felt to be necessary by interviewees from the repair organisation, furniture reuse organisation, compliance scheme and government spokesperson. However, there was some reluctance to assign the production of a standard to producers for fear that it would somehow discourage reuse. Rather, the reuse sector should be consulted more and could prepare standards for reuse, including collection and repair.

The current PAS141 was mentioned, although it was felt this standard was too 'waste-focussed' by reuse organisations and did not really help to improve reuse levels. The Revolve Standard in Scotland was mentioned several times as an example of best practice to encourage resale of goods to a wider audience, and this could improve reuse by implementing this across the UK to give consumers confidence when purchasing reused items.

6.4 Policy Issues

Environmental issues were perceived to be "low down the list of government priorities at the moment" (local authority advisory body). However, the devolved government spokesperson discussed the UN Sustainable Development Goals and "an improvement in the amount, or type of reuse currently being done could be addressed through work to meet these goals." Another government official pointed out that "it is not the process, but the outcomes that are important", so addressing EPR fees, or introducing deposit and return on EEE items returned through retailers may be routes that merit further investigation.

Providing consumers with additional environmental information at point of purchase, through the Packaging Regulations, is an option currently being explored by one devolved government. This would be addition to those currently required by the WEEE Directive and could be expanded to apply to new purchases of EEE. This would ensure more comprehensive information regarding content, use and disposal is given to consumers, including options for repair and reuse.

Several interviewees mentioned fiscal policies such as tax exemptions for repair operations in the form of zero rated VAT, business tax breaks for reuse organisations. In addition, conflicting views of visible PR fees were 
expressed, with one interviewee (environmental lobby group) thinking this would incentivise consumer environmental behaviour and another (local authority advisory body) thinking the opposite.

There was demand for more government guidance on existing policy for the waste management sector, with better regulation to ensure the sector operates correctly within the Duty of Care Regulations. Additionally, compliance schemes should improve relationships with reuse organisations to increase reuse levels.

\section{Conclusion}

Many of the issues explored in this research need to be addressed to increase the quantity of EEE items that are reused and make progress towards reaching their optimum life. These include amending collection systems to enable reusable items to retain their reuse potential and changing consumer behaviour to increase levels of reuse through raising consumer awareness about opportunities for purchasing second hand items or retrieving goods for reuse.

There is much to be done from design, through to production, use and disposal, to address the number of EEE goods that are thrown away before they become unusable. Repair and reuse can assist with this if logistics, knowledge and skills are addressed. This may need to be facilitated through improved legislation to address issues such as design for repairability, barriers to repair which prevent reuse, individual producer responsibility, and appropriate standards for the reuse sector.

Whilst many barriers exist, it was acknowledged by all the interviewees that there are opportunities to increase the reuse of EEE. The challenges around design and accessibility to repairs, with a particular focus on knowledge and skills, are to be addressed in future phases of the research.

\section{Acknowledgements}

The research undertaken was funded by support from EPSRC-funded Centre for Industrial Energy, Materials and Products (CIE-MAP) grant reference EP/N022645/1.

9 Literature

[1] Balde, C.P., Wang, F., Kuehr, R. \& Huisman, J. (2015) The global e-waste monitor - 2014, United Nations University, IAS-SCYCLE, Bonn, Germany.

[2] Hawkins, R.G.P. \& Shaw, H.S. (2004) The practical guide to waste management law. London, Thomas Telford.

[3] Williams, P.T. (2005) Waste treatment and disposal (2nd ed.) Chichester, Wiley

[4] Gaidajis, G., Angelakoglou, K. \& Aktsoglou, D. (2010) E-waste: Environmental problems and current management. Journal of Engineering Science \& Technology Review, 3 (1) 193-199.

[5] Defra (2012) Resource Security Action Plan: Making the most of valuable materials, London, Defra.

[6] Thompson, L. \& Chainey, S. (2011) Profiling Illegal Waste Activity: Using Crime Scripts as a Data

Collection and Analytical Strategy. European Journal on Criminal Policy and Research. 17: 179-201.

[7] WRAP (2009a) Compositional analysis of kerbside collected small WEEE. Banbury, WRAP.

[8] Allwood, J.M., Ashby, M.F., Gutowski. T.G. \& Worrell. E. (2011) Material efficiency: A white paper. Resources, Conservation and Recycling. 55 (3): 362-381.

[9] Cooper, T. (2004) Inadequate life? Evidence of consumer attitudes to product obsolescence. Journal of Consumer Policy. 27: 421-449.

[10] Defra (2011) Public understanding of product lifetimes and durability (1). London, Defra.

[11] Warde, A. (2005) Consumption and theories of practice. Journal of consumer culture. 5 (2) 131-153.

[12] Cooper, T. (2005) Slower consumption reflections on product life spans and the "Throwaway Society”. Journal of Industrial Ecology. 9 (1-2) 51-67.

[13] Allwood J.M. \& Cullen, J.M. (2012) Sustainable Materials with both eyes open, Cambridge, UIT Cambridge. [14] Cui, J. \& Forssberg, E. (2003) Mechanical recycling of waste electric \& electronic equipment: a review. Journal of hazardous materials, 99 (3) 243-263.

[15] WRAP (2012a) Electrical product material composition, Banbury, WRAP.

[16] Blok, K. (2004) Improving energy efficiency by five percent and more per year? Journal of Industrial Ecology, 8 (4) 87-99.

[17] Pettersen, I.N. (2015) Fostering absolute reductions in resource use: the potential role and feasibility of practice-oriented design. Journal of Cleaner Production. doi: 10.1016/j.jclepro.2015.02.005

[18] Binswanger, M. (2001) Technological progress and sustainable development: What about the rebound effect? Ecological Economics. 36: 119-132.

[19] Stern, N. (2009) A blueprint for a safer planet: How to manage climate change and create a new era of progress and prosperity. London, Bodley Head.

[20] Skelton, A.C. \& Allwood, J.M. (2013) Product life trade-offs: what if products fail early? Environmental Science \& Technology. 47(3) 1719-1728.

[21] Tingley, D.D. \& Davison, B. (2011) Design for deconstruction and material reuse. Energy. 164 (4) 195-204.

[22] Evans, S. \& Cooper, T. (2010) Consumer influences on product. Longer lasting products: Alternatives 
to the throwaway society, p.319.

[23] Nelen, D., Manshoven, S., Peeters, J.R., Vanegas, P., D'Haese, N. and Vrancken, K., 2014. A multidimensional indicator set to assess the benefits of WEEE material recycling. Journal of Cleaner Production, 83, 305-316

[24] Curran, A., Williams, I.D. \& Heaven, S. (2007) Management of household bulky waste in England. Resources, Conservation \& Recycling. 51 (1) 78-92.

[25] Allwood, J.M. (2014) Squaring the circular economy: the role of recycling within a hierarchy of material management strategies. In Handbook of Recycling, editors M. Reuter and E Worrell, Elsevier, ISBN: 978-0-12396459-5.

[26] Darby, L. \& Obara, L. (2005) Household recycling behaviour and attitudes towards the disposal of small electrical and electronic equipment. Resources, Conservation and Recycling. 44: 17-35.

[27] Kummer, K., (1992). The international regulation of transboundary traffic in hazardous wastes: The 1989 Basel Convention. International and Comparative Law Quarterly, 41(3) 530-562.

[28] Binnemans, K., Jones, P.T., Blanpain, B., Van Gerven, T., Yang, Y., Walton, A. \& Buchert, M. (2013)

Recycling of rare earths: a critical review. Journal of Cleaner Production. 51: 1-22.

[29] Oguchi, M., Sakanakura, H. \& Terazono, A. (2013) Toxic metals in WEEE: characterization and substance flow analysis in waste treatment processes. Science of the Total Environment. 463: 1124-1132.

[30] Dalrymple, I., Wright, N., Kellner, R., Bains, N., Geraghty, K., Goosey, M. \& Lightfoot, L. (2007) An integrated approach to electronic waste (WEEE) recycling. Circuit World. 33(2) 52-58.

[31] Barr, S., Guilbert, S., Metcalfe, A., Riley, M., Robinson, G.M. \& Tudor, T.L. (2013) Beyond recycling: An integrated approach for understanding municipal waste management. Applied Geography. 39: 67-77.

[32] European Commission (2015) Closing the Loop - An EU action plan for the circular economy, COM/2015/0614 final. Online. Available http://eurlex.europa.eu/legalcontent/

EN/TXT/?uri=CELEX:52015DC0614

[33] Lindhqvist, T. and Lifset, R. (2003) Can we take the concept of individual producer responsibility from theory to practice? Journal of industrial ecology. 7(2) 3-6.

[34] Khetriwal, D.S., Kraeuchi, P. \& Widner, R. (2009) Producer responsibility for e-waste management: Key issues for consideration - Learning from the Swiss experience. Journal of Environmental Management. 90: 153-165.

[35] OECD (1998) Extended Producer Responsibility Phase 2. [online] available at http://www.oecd.org/officialdocuments/publicdisplaydocumentpdf/?doclanguage=en\&cote=env/epoc/ppc(97)19 /rev2 last accessed 15/4/16.

[36] Khetriwal, D.S., Widner, R., Kuehr, R \& Huisman, J. (2011) One WEEE, many species: lessons from the European experience. Waste Management \& Research. 29 (9) 954-962.

[37] Van Rossen, C., Tojo, N. and Lindhqvist, T. (2006) Extended producer responsibility. An examination of its impact on innovation and greening products. Report commissioned by Greenpeace International, Friends of the Earth and the European Environmental Bureau (EEB). The International Institute for Industrial Environmental Economics, Lund.

[38] Dowlatshahi, S. (2000) Developing a theory of reverse logistics. Interfaces. 30 (3) 143-155.

[39] Kissling, R., Fitzpatrick. C., Boeni, H., Luepschen, C.S., \& Dickenson, J. (2012) Definition of generic re-use operating models for electrical equipment. Resources, Conservation \& Recycling. 65: 85- 99.

[40] Achillas, C., Vlachokostas, C., Aidonis, D., Moussiopoulos, N., Iakovou, E. \& Banias, G. (2010) Optimising reverse logistics network to support policy- making in the case of Electrical and Electronic Equipment. Waste Management. 30 (12): 2592-2600.

[41] Mayers, K., Lifset, R., Bodenhoefer, K. \& Van Wassenhove, L. N. (2013). Implementing Individual Producer Responsibility for waste electrical and electronic equipment through improved financing. Journal of Industrial Ecology. 17: 186-198.

[42] Lepawsky, J. (2012) Legal geographies of ewaste legislation in Canada and the US: Jurisdiction, responsibility and the taboo of production. Geoforum 43: 1194-1206.

[43] Nnorom, I.C. \& Osibanjo, O. (2008) Overview of electronic waste (e-waste) management practices and legislations, and their poor applications in the developing countries. Resources, Conservation and Recycling. 52: 843-858.

[44] Ongondo, F.O., Williams, I.D. \& Cherrett, T.J. (2011) How are WEEE doing? A global review of the management of electrical and electronic wastes. Waste Management, 31 (4) 714-730.

[45] Zhang, L. \&Xu, Z. (2016) A review of current progress of recycling technologies for metals from waste electrical and electronic equipment. Journal of Cleaner Production. 127, 19-36.

[46] Cole, C., Osmani, M., Quddus, M., Wheatley, A. \& Kay, K. (2014) Towards a zero-waste strategy for an English local authority. Resources, Conservation and Recycling. 89: 64-75.

[47] Agrawal, S., Singh, R.K. \& Murtaza, Q. (2015) A literature review and perspectives in reverse logistics. Resources, Conservation and Recycling. 97: 76-92. 
[48] WRAP (2016) National municipal waste compositional analysis in Wales. Banbury, WRAP.

[49] Chancerel, P. \& Rotter, S. (2009) Recycling oriented characterization of small waste electrical and electronic equipment. Waste Management, 29 (8) 2336-2352.

[50] Waite, S., Cox, P. \& Tudor, T. (2015) Strategies for local authorities to achieve the EU 2020 50\% recycling, reuse and composting target: A case study of England. Resources, Conservation and Recycling,

105: 18-28.

[51] Dindarian, A., Gibson, A.A.P. \& Quariguasi- Frota-Neto, J. (2012) Electronic product returns and potential reuse opportunities: a microwave case study in the United Kingdom. Journal of Cleaner Production. 32: 22-31.

[52] Lambert, A.F. \& Gupta, S.M., (2004) Disassembly modelling for assembly, maintenance, reuse and recycling. CRC press.

[53] Zuidwijk, R. \& Krikke, H. (2008) Strategic response to EEE returns: Product eco-design or new recovery processes? European Journal of Operational Research. 191(3) 1206-1222.

[54] King, A.M., Burgess, S.C., Ijomah, W., \& McMahon, C.A. (2006) Reducing waste: repair, recondition, remanufacture or recycle? Sustainable Development.14: 257-267.

[55] Dimitrakakis, E., Janz, A., Bilitewski, B. \& Gidarakos, E. (2009) Small WEEE: determining recyclables and hazardous substances in plastics. Journal of hazardous materials. 161(2) 913-919.

[56] Perez-Balis, V., Bovea, M.D. \& Ibanez-Fores, V.

(2015) An in-depth literature review of the waste electrical and electronic equipment context: Trends and evolution. Waste Management \& Research. 33(1)3-29.

[57] WRAP (2012b) Composition of kerbside and HWRC bulky waste, Banbury, WRAP.

[58] WRAP (2011) Realising the reuse value of household WEEE, Banbury, WRAP.

[59] Tavri, P., Sayce, S. \& Hands, V. (2015) Organisational behaviour change towards waste reuse in the UK third sector. The International Journal of Computational Methods and Experimental. 3 (4) 291-304.

[60] Cooper. T (2010) Policies for Longevity, In T Cooper ed., Longer Lasting Products: Alternatives to the Throwaway Society, Gower, Farnham, pp 215-240, 2010.

[61] Stahel, W.R. (1998) Product durability and retake after use. In: Kostecki, M. (Ed.) The durable use of consumer products. Kluwer Academic Publishers. Great Britain, pp 29-40.

[62] British Standards Institute (2011) PAS141: Reuse of used and waste electrical and electronic equipment (UEEE and WEEE) Process Management. London, British Standard Institution.

[63] Quariguasi-Frota-Neto, J., Reade, A., Dindarian, A. \& Gibson, A. (2014) The newly created Publicly Available Specification (PAS 141) for reusable electrical / electronic products: Goals and research needs for successful uptake. Journal of Manufacturing Technology Management. 25(8) 1135-1147.

[64] Alexander, C. \& Smaje, C. (2008). Evaluating third sector reuse organisations in the UK: case studies and analysis of furniture reuse schemes. Resources, Conservation and Recycling. 52 (5): 719-730.

[65] Curran, A. and Williams, I.D. (2010) The role of furniture and appliance re-use organisations in England \& Wales. Resources, Conservation and Recycling. 54(10): 692-703.

[66] Palinkas, L.A., Horwitz, S.M., Green, C.A., Wisdom, J.P., Duan, N. \& Hoagwood, K. (2015) Purposeful sampling for qualitative data collection and analysis in mixed method implementation research. Administration and Policy in Mental Health and Mental Health Services Research, 42(5) 533-544.

[67] Kemper, E. A., Stringfield, S., \& Teddlie, C. (2003) Mixed methods sampling strategies in social science research. In A. Tashakkori \& C. Teddlie (Eds.), Handbook of mixed methods in the social and behavioural sciences (pp. 273-296). Thousand Oaks, CA: Sage.

[68] DiCicco-Bloom, B. \& Crabtree, B. F. (2006) The qualitative research interview. Medical Education. 40: 314321.

[69] Yin, R.K. (2009) Case study research: Design and methods (4th ed.) Sage Publications, London.

[70] Corbin, J. \& Strauss, A. (2014) Basics of qualitative research: Techniques and procedures for developing grounded theory. Sage publications. 